\title{
Proteomic and transcriptomic analysis of heart failure due to volume overload in a rat aorto- caval fistula model provides support for new potential therapeutic targets - monoamine oxidase $\mathrm{A}$ and transglutaminase 2
}

Jiri Petrak ${ }^{1 *}$, Jana Pospisilova ${ }^{1}$, Miroslava Sedinova², Petr Jedelsky², Lucie Lorkova', Ondrej Vit', Michal Kolar ${ }^{3}$, Hynek Strnad ${ }^{3}$, Jan Benes ${ }^{4}$, David Sedmera ${ }^{5,6}$, Ludek Cervenka ${ }^{4,7}$ and Vojtech Melenovsky ${ }^{4}$

\begin{abstract}
Background: Chronic hemodynamic overloading leads to heart failure (HF) due to incompletely understood mechanisms. To gain deeper insight into the molecular pathophysiology of volume overload-induced HF and to identify potential markers and targets for novel therapies, we performed proteomic and mRNA expression analysis comparing myocardium from Wistar rats with HF induced by a chronic aorto-caval fistula (ACF) and sham-operated rats harvested at the advanced, decompensated stage of HF.

Methods: We analyzed control and failing myocardium employing iTRAQ labeling, two-dimensional peptide separation combining peptide IEF and nano-HPLC with MALDI-MS/MS. For the transcriptomic analysis we employed Illumina RatRef-12v1 Expression BeadChip.

Results: In the proteomic analysis we identified 2030 myocardial proteins, of which 66 proteins were differentially expressed. The mRNA expression analysis identified 851 differentially expressed mRNAs.

Conclusions: The differentially expressed proteins confirm a switch in the substrate preference from fatty acids to other sources in the failing heart. Failing hearts showed downregulation of the major calcium transporters SERCA2 and ryanodine receptor 2 and altered expression of creatine kinases. Decreased expression of two NADPH producing proteins suggests a decreased redox reserve. Overexpression of annexins supports their possible potential as HF biomarkers. Most importantly, among the most up-regulated proteins in ACF hearts were monoamine oxidase A and transglutaminase 2 that are both potential attractive targets of low molecular weight inhibitors in future HF therapy.
\end{abstract}

Keywords: Heart failure, hypertrophy, annexins, monoamine oxidase, transglutaminase

\section{Background}

Heart failure (HF) is a major cause of human morbidity and mortality with increasing prevalence worldwide, affecting $2-4 \%$ of the adult European population [1]. HF is a complex syndrome, resulting from an impaired ability of the diseased heart to maintain adequate effective

\footnotetext{
* Correspondence: jpetr@lf1.cuni.cz

1 Institute of Pathological Physiology, First Faculty of Medicine, Charles University, Prague, Czech Republic

Full list of author information is available at the end of the article
}

cardiac output [2]. Typical signs and symptoms of chronic HF are shortness of breath, cough, accumulation of fluids in the lungs and other tissues, fatigue, limitations on physical activity and arrhythmia [2]. The prognosis for affected individuals is poor and $50 \%$ of chronic HF patients die within 4 years of the initial diagnosis [1]. Despite substantial progress in deciphering individual processes involved in the initiation and gradual progression of HF [3], our understanding of the underlying molecular causes of cardiomyocyte dysfunction is 
still very limited. The molecular phenotype of heart failure has been associated with the altered expression of proteins involved in energy metabolism, membrane excitation, calcium-mediated excitation-contraction coupling, force transduction and with myofilament contraction or relaxation [3]. Studies of the molecular mechanisms of HF in humans are undermined by multifactor etiology of cardiac dysfunction, by confounding co-morbid conditions and also by a lack of appropriate healthy controls. These obstacles can be avoided in experimental animal models. In rodents, experimental HF is most often induced by myocardial infarction (ligation of the proximal left coronary artery) or by pressure overload (banding of the proximal aorta). As recently demonstrated the molecular responses to volume and pressure overload appear to differ [4].

HF induced by chronic volume overload has been studied less, despite such overload due to valve insufficiency being relatively common among HF patients [5]. Volume overload due to a surgically created aorto-caval fistula (ACF) in rats is a well defined model of chronic HF [6-8], which mimics the gradual transition of asymptomatic cardiac hypertrophy into symptomatic HF. The creation of an ACF leads to increased cardiac output and eccentric ventricular hypertrophy that remains asymptomatic for 8-10 weeks. Because most of cardiac output is shunted into the inferior vena cava, the effective cardiac output is reduced. leading to renal hypoperfusion [7], neurohumoral activation, and sodium/water retention [8]. Elevated cardiac filling pressures further contribute to cardiac overload [9-11]. By these mechanisms, HF gradually develops [8].

To better elucidate the molecular pathophysiology of HF due to ACF, and to identify potential molecular targets for novel therapies, we performed a proteomic analysis of the left ventricle myocardium from ACF animals with signs of HF (150 days after fistula creation) and control (sham-operated) rats. We used a shot-gun approach that combines iTRAQ labeling chemistry [12] with two-dimensional separation of peptides by isoelectric focusing on immobilized $\mathrm{pH}$ gradients (IEF-IPG) [13] followed by nano-HPLC and MALDI mass spectrometry. The myocardial samples were also subjected to mRNA microarray expression analysis.

\section{Materials and methods}

\section{The chronic HF model}

HF due to volume overload was induced in male Wistar rats (300-350 g) by creating an aorto-caval fistula (ACF) using a $1.2 \mathrm{~mm}$ needle from laparotomy under general anesthesia, as described previously [6,7]. Control sham-operated animals underwent the same procedure, but without creating an ACF. The animals were kept on a 12/12-hour light/dark cycle, and fed a normal salt/protein diet $(0.45 \% \mathrm{NaCl}, 19-21 \%$ protein, SEMED, CR). The investigation conformed to the NIH Guide for the care and use of laboratory animals (NIH Publication No. 85-23, 1996), Animal protection laws of the Czech Republic (311/1997) and was approved by the Ethics Committee of IKEM (305/09/1390 from 25. March 2008).

\section{Echocardiography and hemodynamics}

Examinations were performed under general anesthesia (ketamine+midazolam mixture) at the study end (150 days after ACF creation) prior to harvesting of heart tissue. Echocardiography was performed with a $10 \mathrm{MHz}$ probe (Vivid System 5, GE, USA). End-systolic and enddiastolic left ventricle (LV) volumes were derived by the cubic equation and stroke volume as their difference. Hemodynamics was measured with a $2 \mathrm{~F}$ micro-manometer catheter (Millar Instruments) inserted into the aorta and LV via the carotid artery, connected to a Powerlab 8 platform for off-line analysis with LabChart software (ADInstruments, Germany). The presence of ACF was verified by laparotomy and the animals were killed by exsanguination. After removal, hearts were immediately perfused with ice-cold St. Thomas cardioplegic solution administered into the aortic root. The organs were weighted and normalized to body weight.

\section{Morphological examination}

Perfused hearts were fixed with $4 \%$ paraformaldehyde in phosphate buffer saline (PBS). After $24 \mathrm{~h}$ of immersion in the same fixative, the hearts were rinsed in PBS and processed through ascending series of saccharose prior to embedding into Tissue-Tek OCT medium. The blocks were then cut on cryomicrotome at 12 micrometers thickness. Guide series were stained by hematoxylin-eosin with Alcian blue. Sister sections were then stained with Picrosirius Red. The slides were finally washed with distilled water and dehydrated in ascending ethanol series, cleared in xylene, and mounted in Depex medium. Observation and photography were performed in transmitted and polarized light on an Olympus BX51 compound microscope.

\section{Myocardial sample preparation}

Samples of mid-ventricular anterior free LV wall tissue were immediately harvested into liquid nitrogen and stored at $-80^{\circ} \mathrm{C}$ until analysis. Frozen samples $(\mathrm{ACF}, \mathrm{n}=$ 6 and controls, $n=6$ ) were pulverized under liquid nitrogen and the samples were sub-pooled according to the following scheme: ACF1 (ACF rats \#1,3,5), ACF2 (ACF rats \#2,4,6), Sham1 (sham-operated rats \#1,3,5), Sham2 (sham-operated rats \#2,4,6). The pooled samples $(10 \mathrm{mg})$ were extracted with $1 \mathrm{~mL}$ of NHT buffer (140 $\mathrm{mM} \mathrm{NaCl}, 10 \mathrm{mM}$ Hepes, $1.5 \%$ Triton X-100, pH 7.4) 
for $15 \mathrm{~min}$ on ice. Insoluble material was sedimented at $15000 \times \mathrm{g}$ for $15 \mathrm{~min}$ and the protein concentration of the cleared supernatant was determined by the Bradford assay (Bio-Rad, CA). A $100 \mu \mathrm{g}$ aliquot from each sample was precipitated overnight in cold acetone $\left(-20^{\circ} \mathrm{C}\right)$. Precipitated proteins were sedimented at $15000 \times g$ at $4^{\circ} \mathrm{C}$ for $15 \mathrm{~min}$.

\section{Protein digestion and ITRAQ labeling}

Extracted and acetone-precipitated myocardial samples were reduced, alkylated, digested with trypsin and labeled with 114-117 iTRAQ chemistry according to the manufacturer's instructions (Applied Biosystems, UK). Labeling was performed as follows: "114" - ACF1, "115" - ACF2, "116" - Sham1, "117" - Sham2. Labeled samples 114-117 were then combined and the volume of the final sample was reduced to $40 \mu \mathrm{L}$ in a SpeedVac Concentrator (Eppendorf, CR). In total, three independent analyses A, B and C of the ACF1, ACF2, Sham 1 and Sham 2 samples were performed including extraction, digestion, labeling, separation and MS analysis.

\section{IEF-IPG of peptides, extraction}

Isoelectric focusing was performed on a Protean IEF cell (Bio-Rad, CA, USA) using 24 cm IPG strips (pH 4-7, BioRad). Strips were rehydrated overnight in $450 \mu \mathrm{L}$ of iTRAQ-labeled peptide mixture diluted with rehydration buffer (7 M urea, $2 \mathrm{M}$ thiourea, 4\% CHAPS, $60 \mathrm{mM}$ DTT, $1 \%$ ampholytes and $0.002 \%$ bromophenol blue). IEF was carried out for $73 \mathrm{kVhr}$ with maximum voltage not exceeding $6 \mathrm{kV}$, current limited to $50 \mu \mathrm{A}$ per strip and temperature set to $20^{\circ} \mathrm{C}$. After focusing, strips were briefly washed in water, cut into 32 pieces and peptides were extracted from individual strip pieces into $150 \mu \mathrm{L}$ of $80 \%$ acetonitrile with $0.5 \%$ trifluoroacetic acid, for one hour at room temperature. The volume of all fractions was reduced to $5-10 \mu \mathrm{L}$ by evaporation in the SpeedVac Concentrator and fractions were stored at $-80^{\circ} \mathrm{C}$.

\section{LC-MALDI}

LC-MALDI analyses were performed on an Ultimate 3000 HPLC system (Dionex, Sunnyvale, USA) coupled to a Probot micro-fraction collector (Dionex). Extracted post-IEF fractions were loaded onto a PepMap 100 C18 RP column ( $3 \mu \mathrm{m}$ particle size, $15 \mathrm{~cm}$ long, $75 \mu \mathrm{m}$ internal diameter; Dionex) and separated by a gradient of $3 \%$ $(\mathrm{v} / \mathrm{v})$ acetonitrile, $0.1 \%(\mathrm{v} / \mathrm{v})$ trifluoroacetic acid to $44 \%$ $(\mathrm{v} / \mathrm{v})$ acetonitrile, $0.1 \%(\mathrm{v} / \mathrm{v})$ trifluoroacetic acid over a period of $113 \mathrm{~min}$ and from $44 \%$ to $80 \% \mathrm{ACN}$ over the next $7 \mathrm{~min}$. The flow rate was set to $300 \mathrm{~nL} / \mathrm{min}$. The eluate was mixed 1:3 with matrix solution $(2 \mathrm{mg} / \mathrm{mL} \alpha-$ cyano-4-hydroxycinnamic acid in $80 \% \mathrm{ACN}$ ) by the Probot micro-fraction collector prior to spotting onto a MALDI target (5 spots per minute). Spectra were acquired on a 4800 Plus MALDI TOF/TOF analyzer (AB Sciex) equipped with a Nd:YAG laser (355 nm, firing rate $200 \mathrm{~Hz}$ ). All spots were first measured in MS mode from $\mathrm{m} / \mathrm{z} 800$ to 4,000 and then up to 15 strongest precursors were selected for MS/MS analysis which was performed with $1 \mathrm{kV}$ collision energy and a collision cell operating pressure of $10^{-6}$ Torr. Tandem mass spectra were processed with a 4000 Series Explorer with subtract baseline enabled (peak width 50), Gaussian smoothing enabled (filter width 5), minimum signal to noise 8 , local noise window width $250 \mathrm{~m} / \mathrm{z}$, minimum peak width at full width half max 2.9 bins, cluster area signal to noise optimization enabled (threshold 15), and flag monoisotopic peaks enabled.

\section{Proteomic data analysis}

Mass spectrometry data from all three parallel analyses $\mathrm{A}, \mathrm{B}$ and $\mathrm{C}$ were merged and processed as a single dataset. Protein identification and quantitation were performed using Protein Pilot 3.0 (AB Sciex). MS/MS spectra were searched against the Rattus norvegicus sequences assembly downloaded from GenBank (http:// www.ncbi.nlm.nih.gov/protein, 110358 sequences, as of 06-Jan-2010) with the following settings: Trypsin digestion (semitryptic peptides allowed), methyl methanethiosulfonate modification of cysteines, iTRAQ 4-plex labeled peptides, instrument 4800, no special factors, default iTRAQ isotope correction settings, quantification, bias correction, background correction, biological modifications and thorough ID parameters selected. Probabilities of modifications were not altered. The detected protein threshold (unused protein score and confidence of results) was set to 2.0 and $99.0 \%$ and false discovery rate analysis was enabled. Proteins sharing a set of peptides were grouped automatically with the default Pro Group ${ }^{\mathrm{TM}}$ Algorithm. Ratios of iTRAQ were calculated with default Protein Pilot setting, Protein fold change (iTRAQ ratio for an individual protein) was calculated automatically by the Protein Pilot software as a weighted average of Log iTRAQ ratios determined for individual peptides belonging to the particular protein after background subtraction.

To estimate the false discovery rate (FDR) a decoy database search was performed. For each protein ratio the Protein Pilot reported the p-value and EF (error factor). To be considered as differentially expressed, individual proteins had to fulfill the following statistical criteria: $p$ value $<0.05, E F<2$ and average iTRAQ ratio $>1.5$. In our experimental iTRAQ labeling scheme ("114" - ACF1, "115" - ACF2, "116" - Sham1, "117" Sham2) a protein was considered differentially expressed only when the all three parameters were reached for all four ACF/Sham protein iTRAQ ratios (i.e for all ratios $116 / 115,116 / 114,117 / 115$ and $117 / 114)$. The fold- 
change of differentially expressed proteins was calculated as the average value from the protein iTRAQ ratios reported by Protein Pilot.

\section{Western blotting}

Myocardial protein samples $(20 \mu \mathrm{g})$ were separated on 10 or $12 \%$ SDS-PAGE minigels in Tris-Glycine buffer. Electrophoresis was performed at a constant voltage 90 V. Proteins were then transferred to PVDF membranes (Milipore, MA, USA) in semi-dry blotter (Hoeffer, Canada) at $0.8 \mathrm{~mA} / \mathrm{cm}^{2}$ of membrane. Membranes were incubated in blocking buffer (phosphate buffer saline (Invitrogen, CA) and 0.1\% TWEEN 20 (Sigma-Aldrich)) for 2 hours. Primary antibodies raised against MAO-A (1:300), TGM2 (1:400), HADHA (1:500), from Santa Cruz Biotechnology, CA, USA and GAPDH (1: 330000) from Sigma) were used. After thorough washing in the blocking buffer, secondary horseradish peroxidase-conjugated antibody (1:10 000, Santa Cruz Biotechnology) was added to membrane for one hour. Signal was detected using Western Blotting Luminol Reagent (Santa Cruz Biotechnology).

\section{mRNA expression analysis}

Samples of LV tissue ( $\mathrm{n}=6$ in each group) were immediately harvested into RNA preserving solution (RNALater, Ambiogen, USA). Total RNA was isolated (RNeasy-MicroKit, Qiagen, USA), checked for integrity, amplified, and hybridized on an Illumina RatRef-12v1 Expression BeadChip (Illumina, USA). The raw data were analyzed and processed using the beadarray package of the Bioconductor, as previously described [14]. Analysis of differential expression was performed with the Limmapackage [15] and annotated against the RatRef_12_V1_0_R3_11222119_A.bgx maniphest (Illumina, USA). The cut-off level for differential regulation was set to the fold change [1.5 or 10.67 with Storey q 10.05]. The data are MIAME-compliant and are deposited in the ArrayExpress database (accession \#: EMTAB-190).

\section{Results and Discussion}

We prepared cohorts of rats with an aorto-caval fistula (ACF) and sham-operated control animals. We determined functional and morphological changes in the failing ACF myocardium and performed differential proteomic and mRNA expression analysis of control and failing ACF myocardium.

\section{Cardiac morphometry and function}

Rats with ACF had reached a similar body size as shamoperated controls and most of ACF animals showed clinical signs of HF such as piloerection, lethargy and difficult breathing 150 days after ACF creation.
Compared to controls, ACF animals had markedly increased heart size (Figure 1A) and weights (5.29 \pm 0.18 vs. $2.80 \pm 0.12 \mathrm{~g} / 100 \mathrm{~g}$ of body weight, $\mathrm{p}<0.05$ ) and increased lung weights indicating pulmonary congestion (Table 1). Echocardiography confirmed the enlargement of both ventricles and reduced fractional shortening of the left ventricle. These observations are compatible with incipient contractile dysfunction in ACF. Invasive hemodynamics showed increased end-diastolic LV (left ventricle) pressure also indicative of decompensated HF (Table 1). There was no marked fibrosis observed in ACF hearts (Figure 1B, C), in agreement with a previous report [16].

\section{Proteomic and transcriptomic analysis}

Six male rats with ACF and six sham-operated animals were included into our proteomic analysis and processed in two sub-pooled samples per group. Three

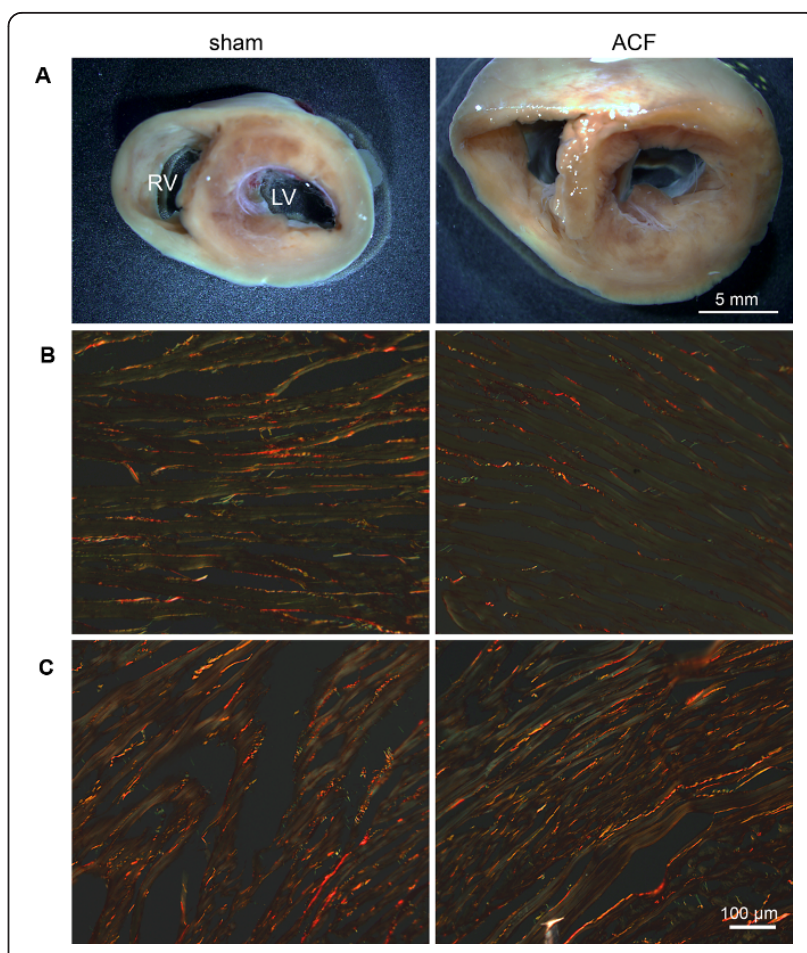

Figure 1 Morphology of sham and ACF rat hearts 150 day after ACF creation. A) Transversal section of the heart illustrates marked biventricular enlargement in the ACF animal compared to control sham-operated rats. B,C) Picrosirius Red staining in transverse sections, observed in polarized light, detected sparse mature collagen fibers (in red) well aligned with the myocyte bundles in the circular layer of the left ventricle (B). The amount of collagen was consistently higher in the right ventricle $(\mathbf{C})$, but no difference between sham and ACF hearts was apparent. Green staining is due to erythrocytes, contractile proteins, or immature collagen fibrils. Very little green was observed at the edges of the collagen fibers, representing physiological protein turnover rather than tissue remodeling, with no difference between sham and ACF. 
Table 1 Morphometric, hemodynamic and echocardiographic characteristics of cardiac function 150 days after ACF

\begin{tabular}{|c|c|c|}
\hline & Sham & ACF \\
\hline \multicolumn{3}{|l|}{ Morphometry } \\
\hline Body weight, $g$ & $592 \pm 20.9$ & $586 \pm 23.4$ \\
\hline Heart weight/BW, g/100 g & $2.80 \pm 0.12$ & $5.29 \pm 0.18 *$ \\
\hline Lung Weight/BW, g/100 g & $3.30 \pm 0.16$ & $4.23 \pm 0.19 *$ \\
\hline \multicolumn{3}{|l|}{ Hemodynamics } \\
\hline Heart rate, $s^{-1}$ & $\begin{array}{c}344.9 \pm \\
13.3\end{array}$ & $360.1 \pm 10.8$ \\
\hline Peak LV pressure, $\mathrm{mmHg}$ & $129 \pm 7.11$ & $120 \pm 3.96$ \\
\hline End-diastolic LV pressure, $\mathrm{mmHg}$ & $6.7 \pm 0.84$ & $12.1 \pm 0.66 *$ \\
\hline \multicolumn{3}{|l|}{ Echocardiography } \\
\hline LV diastolic diameter, mm & $6.08 \pm 0.40$ & $10.20 \pm 0.48$ \\
\hline LV systolic diameter, $\mathrm{mm}$ & $1.95 \pm 0.42$ & $5.47 \pm 0.42 *$ \\
\hline LV Fractional shortening, \% & $69.2 \pm 5.00$ & $46.7 \pm 2.46^{*}$ \\
\hline $\begin{array}{l}\text { LV anterior wall diastolic thickness, } \\
\mathrm{mm}\end{array}$ & $2.30 \pm 0.08$ & $2.33 \pm 0.09$ \\
\hline $\begin{array}{l}\text { LV posterior wall diastolic thickness, } \\
\mathrm{mm}\end{array}$ & $2.33 \pm 0.07$ & $2.31 \pm 0.09$ \\
\hline RV diastolic diameter, $\mathrm{mm}$ & $2.85 \pm 0.18$ & $5.07 \pm 0.29 *$ \\
\hline
\end{tabular}

$\mathrm{n}=10$ /group. Data are mean $\pm \mathrm{SE}$.

BW: Body weight, ACF: aorto-caval fistula group, LV: left ventricle, RV: right ventricle.

* significantly different $(p<0.05)$ than sham-operated animals.

independent labeling and separation experiments $\mathrm{A}, \mathrm{B}$ and $\mathrm{C}$ were performed, resulting in a total 168 LC-runs, collecting over 110,000 MS/MS spectra. Mass spectrometry data from all three parallel analyses were merged and processed as a single dataset by Protein Pilot software. At high confidence (unused protein score 2.0 and confidence 99\%) we identified 2030 individual proteins. For the expression analysis we considered only those proteins that were identified with at least two peptides, each peptide with at least $95 \%$ confidence. That reduced the number of identified proteins to 1446 with a false discovery rate (FDR) of only $0.48 \%$. Based on the proteomic analysis (table 2), sixty six proteins were differentially expressed ( $\mathrm{p}$ value $<0.05$, average iTRAQ ratio $>1.5$ )

Transcriptomic analysis was performed using Illumina chips containing 23,401 rat genes. 16,206 transcripts were tested for differential expression, with 851 being differentially expressed (q-value $<0.05$ ). Complete mRNA expression data are deposited in the ArrayExpress database (accession \#: E-MTAB-190).

Table 2 lists the 66 differentially expressed proteins, along with their respective mRNA expression data. Twenty nine of these proteins were differentially expressed with at least a 1.5-fold change at the mRNA level. Eighteen mRNAs showed less pronounced differential expression but with a trend corresponding with the respective proteins (i.e. up- or down-regulation).
Three proteins were not represented on the array, and the expression of 16 mRNAs out of 66 was not altered.

The list of these 66 differentially expressed proteins including complete iTRAQ and mRNA statistics is available as Additional file 1, examples of 3 peptides used for their identification are as Additional file 2. All other proteins identified in our proteomic analysis are listed in Additional file 3.

We further verified our results by western-blotting analysis of three proteins with potential therapeutic relevance - monoamine-oxidase A (MAO-A), transglutaminase 2 (TGM2) and a key protein of fatty acid beta oxidation - the alpha-subunit of mitochondrial trifunctional enzyme (HADHA) (Figure 2). The results confirm the upregulation of MAO-A and TGM2 and down-regulation of HADHA identified by proteomics and transcriptomics.

\section{Molecular changes in the failing myocardium}

Although contractile function of the heart appears to remain relatively preserved at this stage of $\mathrm{HF}$, our proteomic analysis confirmed characteristic molecular features of HF such as profound changes in heart energetics and metabolism - namely the switch of substrate preference from fatty acids to other substrates are the hallmark of HF $[17,18]$. The largest group of differentially regulated proteins in ACF, representing approximately half of the differentially expressed proteins, is associated with energetic substrate metabolism (Table 2 ). We note the few cases where mRNA expression did not mimic protein changes, or was not present on micro array chips.

\section{Enzymes of fatty acid oxidation and electron transport chain}

The most obvious, but not unexpected, alteration in the failing myocardium was the down-regulation of most key proteins involved in the $\beta$-oxidation of fatty acids (FA). The depressed expression or activity of individual enzymes involved in FA oxidation has been previously demonstrated in advanced HF patients and in most HF models [reviewed in [17] and [18]]. Attenuated myocardial oxidation of palmitate has recently been demonstrated in the same HF model by our group [19]. However, we note that net lipid oxidation can be increased in diabetic cardiac hypertrophy models [20]

We found carnitine O-palmitoyltransferase 2, responsible for the transport of FA across the inner mitochondrial membrane, to be downregulated. The key protein of beta oxidation the mitochondrial trifunctional protein was downregulated (both HADHA and HADHB subunits) as was Acyl-CoA dehydrogenase (3 forms with different FA chain length specificity). Additionally, 32trans-enoyl-CoA isomerase that is responsible for the catabolism of unsaturated FA and Acyl-CoA thioesterase 
Table 2 Proteins differentially expressed in hearts of ACF rats.

\begin{tabular}{|c|c|c|c|c|c|}
\hline & & & Proteins downregulated in ACF & & \\
\hline $\begin{array}{l}\text { Peptides }(95 \% \\
\text { confidence) }\end{array}$ & $\begin{array}{l}\text { Seq. } \\
\text { Cov. }\end{array}$ & Accession & Protein name & $\begin{array}{l}\text { Protein Fold-change } \\
\text { (iTRAQ ratio) }\end{array}$ & $\begin{array}{l}\text { mRNA fold- } \\
\text { change }\end{array}$ \\
\hline 53 & 54 & gi|259435950 & Long-chain-fatty-acid-CoA ligase 1 & 0.23 & NA \\
\hline 17 & 25 & gi|59797483 & Carnitine O-acetyltransferase & 0.24 & 0.52 \\
\hline 124 & 66.1 & gi|189083744 & Sarcomeric mitochondrial creatine kinase & 0.24 & 1.05 \\
\hline 42 & 63 & gi|54035288 & Enolase 3, beta & 0.26 & 0.23 \\
\hline 26 & 52 & gi|57333 & 3-2 trans-enoyl-CoA isomerase & 0.27 & 0.54 \\
\hline 40 & 49 & gi|60688124 & $\begin{array}{l}\text { Trifunctional enzyme subunit alpha, mitochondrial } \\
\qquad(\mathrm{HADHA})\end{array}$ & 0.3 & 0.54 \\
\hline 24 & 35 & gi|31077132 & Histidine rich calcium binding protein & 0.31 & 0.61 \\
\hline 9 & 37 & gi|1906812 & Inducible carbonyl reductase & 0.32 & 0.45 \\
\hline 49 & 65 & gi|56541110 & Acyl-Coenzyme A dehydrogenase, very long chain & 0.33 & 0.59 \\
\hline 28 & 45 & gi|510110 & $\begin{array}{c}\text { Trifunctional enzyme subunit beta, mitochondrial } \\
\text { (HADHB) }\end{array}$ & 0.33 & 0.56 \\
\hline 4 & 17 & gi|66910891 & $\begin{array}{c}\text { Glutamic-pyruvate transaminase (alanine } \\
\text { aminotransferase) }\end{array}$ & 0.34 & 0.38 \\
\hline 113 & 53 & gi|57303 & Sarcoplasmic reticulum 2+-Ca-ATPase (SERCA2) & 0.35 & 1.0 \\
\hline 40 & 56.8 & gi|149042663 & Sarcalumenin & 0.36 & 0.91 \\
\hline 20 & 41.1 & gi|77993368 & Acyl-CoA synthetase family member 2 precursor & 0.39 & NA \\
\hline 120 & 74.3 & gi|6978661 & Muscle creatine kinase & 0.4 & 0.69 \\
\hline 195 & 75.8 & gi|83300587 & ATP synthase subunit alpha, mitochondrial; & 0.4 & 0.71 \\
\hline 120 & 71 & gi|62079055 & Isocitrate dehydrogenase 2 (NADP+) & 0.41 & 0.62 \\
\hline 30 & 50 & gi|7387725 & $\begin{array}{c}\text { Medium and short chain L-3-hydroxyacyl-coenzyme A } \\
\text { dehydrogenase }\end{array}$ & 0.43 & 0.37 \\
\hline 18 & 47.5 & gi|51260066 & Propionyl coenzyme A carboxylase, beta polypeptide & 0.43 & 0.84 \\
\hline 19 & 39 & gi|6166586 & Acyl-coenzyme A thioesterase 2 & 0.44 & 0.54 \\
\hline 24 & 42.6 & gi|149050263 & Propionyl-CoA carboxylase alpha chain & 0.44 & 0.91 \\
\hline 35 & 40.7 & gi|6978543 & $\mathrm{Na}+/ \mathrm{K}+$-ATPase alpha 1 subunit precursor & 0.45 & 1.1 \\
\hline 34 & 64 & gi|56929 & Pyruvate kinase M1/M2 & 0.46 & 0.6 \\
\hline 16 & 37 & gi|62825891 & Phosphofructokinase, muscle & 0.46 & 0.5 \\
\hline 42 & 68.8 & gi|57527204 & Electron-transfer-flavoprotein, alpha polypeptide & 0.46 & 0.69 \\
\hline 10 & 30 & gi|149062241 & LRP16 protein & 0.47 & 0.38 \\
\hline 35 & 47.9 & gi|92090591 & Glutamate dehydrogenase 1 & 0.47 & 0.84 \\
\hline 13 & 43 & gi|6981396 & $\begin{array}{c}\text { Protein kinase, CAMP dependent regulatory, type I, } \\
\text { alpha }\end{array}$ & 0.47 & 1.0 \\
\hline 68 & 37 & gi|61557127 & Nicotinamide nucleotide transhydrogenase & 0.48 & 0.67 \\
\hline 111 & 69.1 & gi|6978431 & Long-chain acyl-CoA dehydrogenase precursor & 0.49 & 0.84 \\
\hline 31 & 49 & gi|48734846 & $\begin{array}{c}\text { Acyl-Coenzyme A dehydrogenase, C-2 to C-3 short } \\
\text { chain }\end{array}$ & 0.53 & 0.58 \\
\hline 64 & 44.5 & gi|81883712 & 2-oxoglutarate dehydrogenase E1 component & 0.53 & 0.69 \\
\hline 48 & 67 & gi|149027156 & Acetyl-Coenzyme A acyltransferase 2 & 0.54 & 0.61 \\
\hline 45 & 25.9 & gi|189181710 & Ryanodine receptor 2, cardiac & 0.58 & 0.79 \\
\hline 30 & 37 & gi|81871846 & $\begin{array}{l}\text { Leucine-rich PPR motif-containing protein, } \\
\text { mitochondrial }\end{array}$ & 0.61 & 0.66 \\
\hline \multirow[t]{2}{*}{33} & 45 & gi|6978705 & Carnitine O-palmitoyltransferase precursor & 0.61 & 0.58 \\
\hline & & & Proteins upregulated in $\mathrm{ACF}$ & & \\
\hline $\begin{array}{l}\text { Peptides }(95 \% \\
\text { confidence) }\end{array}$ & $\begin{array}{l}\text { Seq. } \\
\text { Cov. }\end{array}$ & Accession & Protein name & $\begin{array}{l}\text { Protein Fold-change } \\
\text { (iTRAQ ratio) }\end{array}$ & $\begin{array}{l}\text { mRNA fold- } \\
\text { change }\end{array}$ \\
\hline 44 & 55 & gi|48425083 & Monoamine Oxidase A & 4.06 & 1.93 \\
\hline 10 & 18 & gi|55249666 & Cadherin 13 & 3.40 & 2.15 \\
\hline 19 & 34 & gi|5326787 & Transglutaminase 2 & 3.07 & 1.93 \\
\hline 24 & 61 & gi|94400790 & Heat shock protein 1 (HSP27) & 3.05 & 1.41 \\
\hline
\end{tabular}


Table 2 Proteins differentially expressed in hearts of ACF rats. (Continued)

\begin{tabular}{|c|c|c|c|c|c|}
\hline 23 & 72.2 & gi|438878 & tropomyosin & 3.04 & 1.32 \\
\hline 10 & 42 & gi|6978501 & Annexin A1 & 3.00 & 2.23 \\
\hline 35 & 69.6 & gi|535069 & Muscle LIM protein [Rattus norvegicus] & 2.97 & 1.31 \\
\hline 22 & 50 & gi|6981324 & Prolyl 4-hydroxylase, beta polypeptide & 2.91 & 1.27 \\
\hline 59 & 73.3 & gi|56388799 & Brain creatine kinase (Ckb protein) & 2.88 & 1.31 \\
\hline 16 & 30 & gi|149048530 & Ceruloplasmin, isoform CRA_a & 2.80 & 2.02 \\
\hline 34 & 62.3 & gi|744592 & Alpha-B crystallin & 2.61 & 1.05 \\
\hline 35 & 68 & gi|157830232 & Annexin $\mathrm{V}$ & 2.58 & 1.71 \\
\hline 20 & 27.3 & gi|462569 & Microtubule-associated protein $1 \mathrm{~A}$ & 2.58 & 1.30 \\
\hline 10 & 26.9 & gi|158706096 & $\begin{array}{c}\text { Pre-B-cell leukemia transcription factor-interacting } \\
\text { protein } 1\end{array}$ & 2.45 & 1.23 \\
\hline 8 & 34.4 & gi|68837285 & $\begin{array}{c}\text { D-beta-hydroxybutyrate dehydrogenase, } \\
\text { mitochondrial; }\end{array}$ & 2.44 & 1.02 \\
\hline 10 & 28 & gi|974168 & Aldehyde dehydrogenase $1 \mathrm{~A} 1$ (retinal dehydrogenase & 2.43 & 1.84 \\
\hline 11 & 28 & gil7533042 & Guanine deaminase & 2.41 & 2.02 \\
\hline 8 & 28.9 & gi|57241 & Sulfated glycoprotein 2 (clusterin) & 2.39 & 1.34 \\
\hline 24 & 38.6 & gi|6981022 & Hexokinase 1 & 2.23 & NA \\
\hline 59 & 64.4 & gi|109468300 & Alpha-enolase (Enolase 1) & 2.23 & 1.00 \\
\hline 94 & 50.7 & gi|149063941 & Beta myosin heavy chain myo7 & 2.22 & 1.02 \\
\hline 14 & 35.3 & gi|53237076 & EH-domain containing 4 & 2.22 & 1.08 \\
\hline 22 & 50 & gi|9845234 & Annexin A2 & 2.21 & 2.17 \\
\hline 11 & 25 & gi|149018456 & Microtubule-associated protein 4 & 2.18 & 1.24 \\
\hline 6 & 26 & gi|158186676 & Calumenin isoform a & 2.17 & 0.86 \\
\hline 39 & 42.6 & gi|54673763 & $\begin{array}{c}\text { Heat shock protein 90, alpha (cytosolic), class A } \\
\text { member } 1\end{array}$ & 2.14 & 1.27 \\
\hline 13 & 60.8 & gi|1051270 & 14-3-3 zeta isoform & 1.99 & 1.18 \\
\hline 11 & 33.2 & gi|55855 & Calreticulin & 1.90 & 1.18 \\
\hline 41 & 26.9 & gi|62646949 & Filamin-C (Gamma-filamin) (Filamin-2) & 1.87 & 1.21 \\
\hline 18 & 39.1 & gi|157819677 & Sarcolemma associated protein & 1.81 & 1.02 \\
\hline
\end{tabular}

Identification of all proteins was based on at least four peptides. (for peptide sequences see Additional data 2). NA- mRNA not represented on the chip.

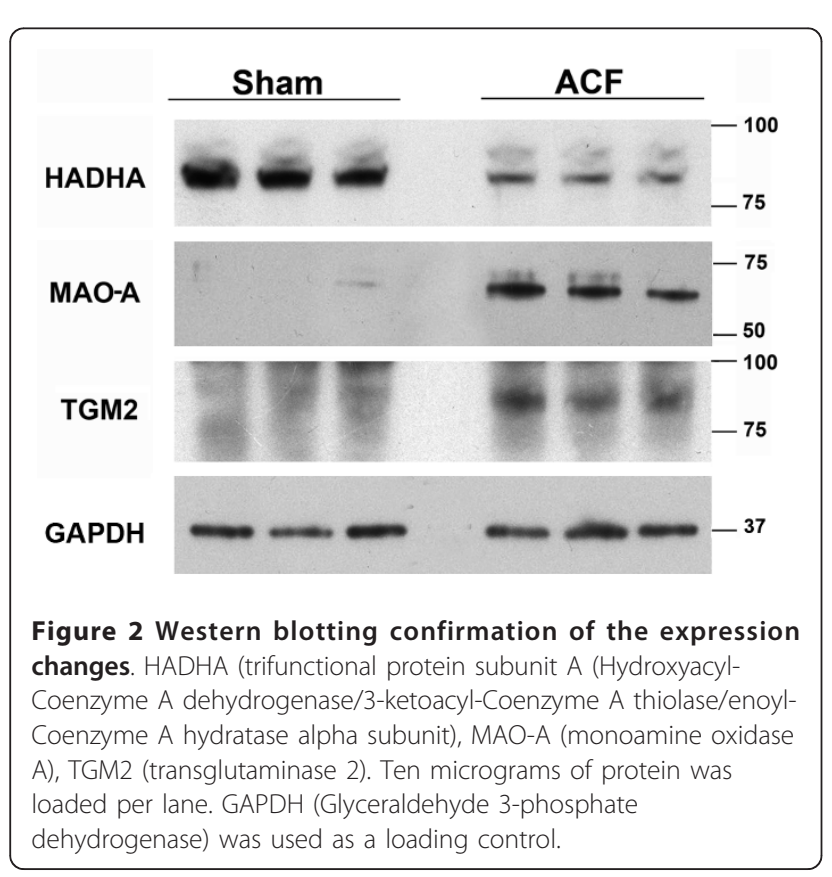

(mitochondrial thioesterase, MTE-1), an enzyme responsible for the intra-mitochondrial generation of free FA anions from acyl-CoAs were both down-regulated in ACF. ACF animals in this study also showed significant downregulation of long-chain acyl-CoA synthetase 1 and acyl-CoA synthetase family member 2 precursor responsible for the initial binding of fatty acids to the coenzyme A moiety, however, their mRNAs were not represented on the Illumina chip.

\section{Glycolysis}

Despite the existence of functional studies suggesting that a failing heart preferentially utilizes glucose [17], we found no convincing evidence of up-regulation of the glycolytic pathway in ACF. The key regulatory enzyme and the last enzyme of glycolysis - phosphofructokinase and pyruvate kinase, were both down-regulated in ACF. Failing hearts also showed decreased expression of muscle-specific enolase-3 ( $\beta$ form) but an increased abundance of the ubiquitous enolase-1 (no change at the mRNA level). 


\section{Creatine kinase system}

We observed decreased abundance of sarcomeric mitochondrial (sMt-CK, no change observed at the mRNA level) and muscle (M-CK) creatine kinase along with upregulation of the $B$-CK isoform (1.3-fold up-regulation of mRNA) changes typical for animal and human HF [21]. Expression of the three corresponding mRNAs is in agreement with these trends. The CK system serves as a temporal buffer of high-energy phosphates (sMt-CK), and participates in an spatial enzymatic network (MCK) responsible for the fast transport of high-energy phosphates from mitochondria to the contractile machinery [22,23]. Decreased CK levels may contribute to the diminished ATP flux via CK observed in HF [23] and contribute to the limited cardiac functional reserve.

\section{Sarcomeric and Calcium handling and proteins}

Of the sarcomeric proteins, we observed up-regulation of the $\beta$-myosin heavy chain (myosin 7 , (no change observed at mRNA level). The switch of the predominant myosin heavy chain from the $\alpha$ - to $\beta$-isoform affects the contractile phenotype, and is considered a hallmark of myocardial HF-induced remodeling [3]. The failing myocardium is also characterized by the diminished expression of proteins responsible for sarcoplasmic reticulum (SR) $\mathrm{Ca}^{2+}$ uptake, handling and release [24]. Correspondingly, we observed marked down-regulation of SR calcium ATPase (SERCA2) protein (no change observed at the mRNA level) and of the main SR $\mathrm{Ca}^{2+}$ release channel - Ryanodine Receptor 2 protein (RYR2) ( 0.79 fold down-regulation of mRNA) thus confirming the molecular HF phenotype in ACF rats. Down-regulation of both proteins in HF has been described previously and was implicated in diminished contractility, reduced $\mathrm{SR} \mathrm{Ca}^{2+}$ stores and less efficient energy utilization of $\mathrm{Ca}^{2+}$ handling $[25,26]$.

\section{Redox state and stress-response related proteins}

Abnormalities in the intracellular redox state have been implicated in most processes affecting cardiac function and the development of HF [27]. The antioxidant potential of the cell is determined by the content of reduced and oxidized glutathione (GSH and GSSG). A sufficiently high GSH/GSSG ratio is maintained by NADPHdependent glutathione reductase. In cardiomyocytes, $\mathrm{NADPH}$ is produced by nicotinamide nucleotide transhydrogenase, isocitrate dehydrogenase, and the pentosephosphate pathway. Interestingly, mitochondrial nicotinamide nucleotide transhydrogenase (NNT), which accounts for up to $45 \%$ of the total NADPH supply [28], was markedly down-regulated in ACF animals. In addition, NADP-dependent isocitrate dehydrogenase (IDH2) which may further contribute to NADPH levels, was also down-regulated. Our observations led us to hypothesize that decreased expression of the two important NADPH producers could compromise the function of glutathione reductase, explaining the attenuated redox reserve. We recently demonstrated decreased GSH/GSSG ratio in the failing ACF myocardium [19], providing support to this idea.

\section{Other proteins}

Three members of the large annexin family: Annexin A5, $A 2$ and $A 1$ were up-regulated. Annexins are ubiquitous proteins associated with the inner cytoplasmatic membrane that are known to bind phospholipids in a $\mathrm{Ca}^{2+}$-dependent manner and to participate in a variety of membrane-related events [29] as well as in apoptosis, inflammation and coagulation. The role of annexins in cardiac physiology remains largely unknown. Interestingly, all three annexins (A1, A2 and A5) that were upregulated in ACF hearts in our study have been previously implicated in calcium-dependent "cell membrane resealing". Such resealing may be relevant in hemodynamically-overloaded hearts with increased mechanical stress [[30] and references within]. Annexin A5 (expressed mostly in cardiomyocytes) and annexin $A 2$ (detected only in endothelial cells and the extracellular matrix) but not annexin $A 1$ have been previously reported to be up-regulated in hypertrophic and failing hearts [29]. Increased serum levels of annexin A5 has been demonstrated in a large study on heart disease patients and was considered to be a potential marker for hypertension-related HF [31]. However, authors of the study however failed to detect increased annexin A5 mRNA in the hearts, raising a question about the source of the protein. Here we demonstrate up-regulation of A1, A2 and A5 transcripts, which further supports these annexin proteins as potential HF markers.

The ACF myocardium displayed up-regulation of Cadherin 13 (T-cadherin). Until recently, its heart-related function has been unknown. This GPI-anchored, lipidraft associated member of the cadherin superfamily recruits adiponectin to heart, and is critical for adiponectin-mediated cardioprotection [32]. Increased expression here can be explained as an adaptive compensation for altered levels of circulating adiponectin [33].

\section{Potential therapeutic targets}

Among the most markedly up-regulated proteins in our study are transglutaminase 2 and monoamine oxidase A. Since both proteins carry promising therapeutic potential we discuss them in detail.

Transglutaminase 2 (TGM2) was up-regulated 3-fold in ACF hearts. TGM2 is a multifunctional protein with G-protein function, disulfide-isomerase and transglutaminase activities, found predominantly in the cytosol and at the cell curface. The transglutaminase activity of this protein is responsible for stable cross-linking of peptide chains between lysine and glutamine residues involved in extracellular matrix stabilization and wound 
healing as well as during apoptosis [34,35]. Due to its Gprotein properties, TGM2 participates in intracellular signaling via $\alpha 1$-adrenergic and thromboxane receptors [34], and has been recently shown to promote apoptosis of rat cardiomyocytes under oxidative stress [36]. Two independent groups have demonstrated that heart-specific TGM2 over-expression results in detrimental hemodynamic changes, structural alterations, cardiomyocyte apoptosis, cardiac hypertrophy and fibrosis [37,38]. Our observation of up-regulated TGM2 in ACF hearts thus adds further evidence for the adverse effect of TGM2 up-regulation in cardiac hypertrophy and HF. Effective low molecular weight inhibitors such as cystamine and monodansylcadaverine are already known and their use inhibits TGM2-induced apoptosis in aortic smooth muscle cells [39] and partially repressed hypoxia-induced cardiac hypertrophy in rats [40]. This highlights the potential of TGM2 as a novel therapeutic target.

\section{Monoamine oxidase A}

The most up-regulated (4-fold) protein in ACF heart is mitochondrial monoamine oxidase-A (MAO-A), an enzyme responsible for oxidative deamination of bioactive monoamines (epinephrine, norepinephrine, serotonin), giving rise to hydrogen peroxide and toxic aldehyde metabolites that are further catabolized by aldehyde dehydrogenases [41]. In concordance with this, aldehyde dehydrogenase $1 A 1$ was also found to be upregulated in ACF hearts in our study. The hydrogen peroxide produced by cardiac MAO-A has been shown to contribute to cardiomyocyte apoptosis [42]. Kaludercic et al. recently demonstrated that increased MAOA-dependent catabolism of norepinephrine contributes to adverse remodeling in pressure-overloaded hearts. Pharmacological inhibition of MAO-A by clorgyline prevents left ventricle dilatation and dysfunction, attenuated oxidative stress and increased norepinephrine myocardial content in pressure overloaded hearts [43]. In an identical model to ours, Kristen et al. showed that ACF rats have increased circulating norepinephrine levels, but depleted cardiac norepinephrine stores [44]. In combination with the studies discussed above, our findings suggest that besides the loss of sympathetic nerve endings [44] or attenuated norepinephrine reuptake [45], myocardial norepinephrine depletion in HF may result from its increased catabolism by MAO-A. This process is common to both pressure and volume overload, and along with tissue norepinephrine depletion causes oxidative damage to cardiomyocytes. Interestingly, MAO-A has also been recently identified as a causal agent of oxidative myofibril damage in muscular dystrophy [46]. All experimental evidence summarized in a recent review [47] along with our observations strongly indicates that MAO-A expression/activity is a major contributor to cardiac hypertrophy and HF. Low-molecular weight inhibitors of MAO-A such as moclobemide exist and are already in clinical use as antidepressants [48]. Therefore, targeted inhibition of MAO-A activity should be intensively investigated as a potential therapy for HF.

\section{Proteins with no previous association with HF}

Of the 66 differentially expressed proteins at least 6 molecules have not been previously associated with heart HF and might therefore be new players in the disease development or progression. No previous connection with HF has been made for inducible carbonyl reductase, LRP16 (a compound of the NF- $\kappa \mathrm{B}$ transcriptional complex) [49] or Leucine-rich PPR motif-containing protein (a regulator of mitochondrial transcription) [50] all down-regulated in ACF. These molecules seem to be involved in metabolic and regulatory processes, but information available on these three molecules is very limited. The up-regulated regulatory protein Pre- $B$ cell leukemia transcription factor-interacting protein alias HPIP (1.3 -fold up-regulation of mRNA) has been previously studied in the context of MAPK and AKT activation and estrogen receptor $(E R \alpha)$ and tubulin binding [51], but no connection with heart has been made to date. The up-regulated proteins guanine deaminase and ceruloplasmin although well known, also have yet to be connected with HF. Ceruloplasmin is a copper binding protein with ferroxidase activity, its altered expression thus may point out toward altered copper or iron homeostasis in HF. Notably copper metabolism or balance appears to be disrupted in diabetic hypertrophied hearts, and copper chelation has been shown to improve heart diabetic cardiac function [52]. The individual roles of these potential new players in the molecular puzzle of HF remain to be determined in future targeted studies.

\section{Conclusions}

To our knowledge, our shot-gun study employing peptide IEF combined with nanoLC-MALDI is the largest (over 2000 proteins) semi-quantitative analysis of proteome changes related to $\mathrm{HF}$ to date. We are aware that our experimental design using two sub-pooled controls and two ACF sub-pools is not typical. This design was driven by our aim to penetrate deeper into mediumand low-abundance proteome and maximize the number of reliably identified and quantified proteins. Merging of MS data from three biologically identical runs provided us with a higher number of identified proteins with higher sequence coverage, and simultaneously increased the number of observed iTRAQ reporter quartets for each protein, thus increasing the reliability of the quantitative information. Our second reason for using this approach is economic. A higher statistical power for the experiment could have been achieved with iTRAQ 
quadruplex by analysis of one control pool against three individual ACF animals (or three ACF subpools). However, such a single control (sham-operated animals) pool would have to consist of many animals to eliminate the risk of a single atypical rat affecting the composition of such a representative control pool. Unfortunately, to operate and maintain large cohorts of such animals for almost half a year is economically prohibitive.

Various proteomics strategies have provided several important "snapshots" of different stages and types of heart hypertrophy and HF resulting from diverse initial insults, different underlying molecular mechanisms, and in different animal models. In this respect the results of different proteomic analyses are difficult to compare. However, the similarity of our results with the work of Grant et al. [53], who used an analogical proteomic approach to examine effect the of aging on the cardiac proteome in old versus young rats, is very intriguing. Similar to our results, aged hearts showed the down-regulation of enzymes of fatty acids oxidation, SMt- and M- creatine kinase, electron-transferring flavoprotein and ATP synthase components. Also in agreement with our study, aged hearts displayed up-regulated $\beta$-myosin heavy chain, muscle LIM protein, microtubule associated proteins 1 and 4, calumenin, calreticulin, annexin 5, prolyl-4-hydroxylase beta subunit, HSP 27 and alpha$\mathrm{B}$ crystallin. Based on the high concordance of proteomic alterations induced by spontaneous aging and by overload-induced HF, it is tempting, however speculative, to view the HF developed in our model as a sort of accelerated, premature aging of the organ.

We are fully aware that our study has one significant limitation. Being based on a pair-wise comparison our study lacks important temporal information and can not discriminate between processes of compensatory hypertrophy and later events of HF itself. To access such a temporal information on the development process and gradual progression of HF, more time points will have to be analyzed in the future.

In summary, we identified multiple enzymes involved in substrate metabolism in the HF myocardium. This confirms many previous observations and is in accordance with altered substrate preference in the HF $[17,18]$. These alterations probably reflect the activation of a prosurvival program of stressed cells, and at least some changes may be adaptive, maximizing cardiac efficiency. Our study brings a novel observation suggesting an attenuated redox reserve (down-regulation of NADPH producers) in ACF rats which possibly contributes to the myocardial remodeling in HF due to oxidative stress. Further, we propose new potential biomarkers of hypertrophy and/or HF (annexin A2 and A1) and, most importantly, suggest two highly potential therapeutic targets for the treatment of HF - monoamine oxidase A and transglutaminase 2. Our work has also identified several proteins, new in the context of HF, as leads for specific, hypothesis-driven experiments.

\section{Additional material}

\section{Additional file 1: Additional data 1_ statistics of differentially expressed proteins and mRNAs.pdf. Table presents statistical significance data on the differential expression of individual proteins (iTRAQ ratios) and their respective mRNA expression.}

Additional file 2: Additional data 3_peptides used for protein identifications .pdf. Table shows sequences of three of the $n$ peptides used for the identification of the 66 differentially expressed proteins.

Additional file 3: Additional data 3_all identified proteins.pdf. Extensive table summarizes all other proteins (not differentially expressed) identified by MS including their accession numbers, sequence coverage and number of peptides observed.

\section{Abbreviations}

HF: Heart Failure; ACF: Aorto-caval fistula; LV: Left ventricle; FA: fatty acids; TGG: transglutaminase 2; MAO-A: monoamine oxidase A; HADHA: Hydroxyacyl-Coenzyme A dehydrogenase/3-ketoacyl-Coenzyme A thiolase/ enoyl-Coenzyme A hydratase alpha subunit; SERCA2: sarcoplasic reticulum ${ }^{2}$ ${ }^{+}$Ca ATPase.

\section{Acknowledgements}

This work was supported by the Grant agency of the Czech Republic 305/ 09/1390, by the EU Operational Program Prague - Competitiveness; project "CEVKOON" (CZ.2.16/3.1.00/22126), and by grants from the Ministry of Health CR (MZO-00023001, 00023736, IGA MZCR NS10300-3, NS10497-3/2009, NT 12248-5; from the Ministry of Education (MSMT-1MO510, VZ 0021620806, 0021620858, LC06044 and SW-2011-262507) and also by the Academy of Sciences of the Czech Republic (AV0Z50110509). We thank to Mrs. Petra Skaroupkova for invaluable help with rat surgical techniques. Special thanks also to Mrtva Ryba.

\section{Author details}

${ }^{1}$ Institute of Pathological Physiology, First Faculty of Medicine, Charles University, Prague, Czech Republic. 'Faculty of Science, Charles University, Prague, Czech Republic. ${ }^{3}$ Institute of Molecular Genetics, Academy of Sciences of the Czech Republic, Prague, Czech Republic. ${ }^{4}$ Department for Experimental Medicine and Department of Cardiology, Institute for Clinical and Experimental Medicine-IKEM, Prague, Czech Republic. ${ }^{5}$ Institute of Anatomy, First Faculty of Medicine, Charles University, Prague, Czech Republic. ${ }^{6}$ Institute of Physiology, Academy of Sciences of the Czech Republic, Prague, Czech Republic. ${ }^{7}$ Department of Physiology, $2^{\text {nd }}$ Medical Faculty, Charles University, Prague, Czech Republic.

\section{Authors' contributions}

JP and VM designed the study, interpreted the data and wrote the manuscript. JaP, LL and OV performed the sample preparation, peptide labeling and separation, and western blotting experiments. MS and PJ performed the LC-MS analysis. VM, JB, LC and DS prepared the ACF animals, measured the hemodynamic and echocardiographic paramaters and performed the morphological analysis. MK and HS were responsible for the mRNA chip analysis. All authors read and approved the final manuscript.

\section{Competing interests}

The authors declare that they have no competing interests.

Received: 22 July 2011 Accepted: 11 November 2011

Published: 11 November 2011

\section{References}

1. Dickstein $K$, Cohen-Solal A, Filippatos G, McMurray JJ, Ponikowski P, PooleWilson PA, Strömberg A, van Veldhuisen DJ, Atar D, Hoes AW, Keren A, 
Mebazaa A, Nieminen M, Priori SG, Swedberg K: Committee for Practice Guidelines (CPG). ESC guidelines for the diagnosis and treatment of acute and chronic heart failure 2008: the Task Force for the diagnosis and treatment of acute and chronic heart failure 2008 of the European Society of Cardiology. Eur J Heart Fail 2008, 10:933-989.

2. McMurray JJ, Pfeffer MA: Heart failure. Lancet 2005, 365:1877-1889.

3. Mudd JO, Kass DA: Tackling heart failure in the twenty-first century. Nature 2008, 451:919-928.

4. Toischer K, Rokita AG, Unsold B, Zhu W, Kararigas G, Sossalla S, Reuter SP, Becker A, Teucher N, Seidler T, Grebe C, Preuss L, Gupta SN, Schmidt K, Lehnart SE, Krüger M, Linke WA, Backs J, Regitz-Zagrosek V, Schäfer K, Field $L$, Maier LS, Hasenfuss G: Differential cardiac remodeling in preload versus afterload. Circulation 2010, 122:993-1003.

5. Trichon BH, Felker GM, Shaw LK, Cabell CH, O'Connor CM: Relation of frequency and severity of mitral regurgitation to survival among patients with left ventricular systolic dysfunction and heart failure. Am J Cardiol 2003, 91:538-543.

6. Garcia R, Diebold S: Simple, rapid, and effective method of producing aortocaval shunts in the rat. Cardiovasc Res 1990, 24:430-432.

7. Flaim SF, Minteer WJ, Nellis SH, Clark DP: Chronic arteriovenous shunt: evaluation of a model for heart failure in rat. Am J Physiol 1979, 236: H698-704.

8. Brower GL, Janicki JS: Contribution of ventricular remodeling to pathogenesis of heart failure in rats. Am J Physiol Heart Circ Physiol 2001, 280:H674-683.

9. Ruzicka M, Yuan B, Leenen FH: Effects of enalapril versus losartan on regression of volume overload-induced cardiac hypertrophy in rats. Circulation 1994, 90:484-491.

10. Ryan TD, Rothstein EC, Aban I, Tallaj JA, Husain A, Lucchesi PA, Dell'Italia LJ: Left ventricular eccentric remodeling and matrix loss are mediated by bradykinin and precede cardiomyocyte elongation in rats with volume overload. J Am Coll Cardiol 2007, 49:811-821.

11. Brower GL, Henegar JR, Janicki JS: Temporal evaluation of left ventricular remodeling and function in rats with chronic volume overload. Am J Physiol 1996, 271:H2071-2078.

12. Gygi SP, Rist B, Gerber SA, Turecek F, Gelb MH, Aebersold R: Quantitative analysis of complex protein mixtures using isotope-coded affinity tags. Nat Biotechnol 1999, 17:994-999.

13. Lengqvist J, Uhlen K, Lehtio J: iTRAQ compatibility of peptide immobilized pH gradient isoelectric focusing. Proteomics 2007, 7:1746-1752.

14. Strnad H, Lacina L, Kolar M, Cada Z, Vlcek C, Dvorankova B, Betka J, Plzak J, Chovanec M, Sachova J, Valach J, Urbanova M, Smetana K Jr: Head and neck squamous cancer stromal fibroblasts produce growth factors influencing phenotype of normal human keratinocytes. Histochem Cell Biol 2010, 133:201-211.

15. Smyth GK: Limma: linear models for microarray data. In Bioinformatics and computational biology solutions using $R$ and Bioconductor. Edited by: Gentleman V, Careyand S, Dudoid S, Irizarry R, Huber W. New York: Springer; 2005:397-420.

16. Benes J Jr, Melenovsky V, Skaroupkova P, Pospisilova J, Petrak J, Cervenka L, Sedmera D: Myocardial Morphological Characteristics and Proarrhythmic Substrate in the Rat Model of Heart Failure Due to Chronic Volume Overload. Anat Rec (Hoboken) 2011, 294:102-111.

17. Stanley WC, Recchia FA, Lopaschuk GD: Myocardial substrate metabolism in the normal and failing heart. Physiol Rev 2005, 85:1093-1129.

18. Lopaschuk GD, Ussher JR, Folmes CD, Jaswal JS, Stanley WC: Myocardial fatty acid metabolism in health and disease. Physiol Rev 2010, 90:207-258.

19. Melenovsky V, Benes J, Skaroupkova P, Sedmera D, Strnad H, Kolar M, Vlcek C, Petrak J, Benes J Jr, Papousek F, Oliyarnyk O, Kazdova L, Cervenka L: Metabolic characterization of volume overload heart failure due to aorto-caval fistula in rats. Mol Cell Biochem 2011, 354:83-96.

20. Jüllig M, Hickey AJ, Middleditch MJ, Crossman DJ, Lee SC, Cooper GJ: Characterization of proteomic changes in cardiac mitochondria in streptozotocin-diabetic rats using iTRAQ $^{\mathrm{TM}}$ isobaric tags. Proteomics Clin Appl 2007, 1:565-576.

21. Ingwall JS, Weiss RG: Is the failing heart energy starved? On using chemical energy to support cardiac function. Circ Res 2001, 95:135-145.

22. Dzeja PP, Terzic A: Phosphotransfer networks and cellular energetics. Exp Biol 2003, 206:2039-2047.
23. Smith CS, Bottomley PA, Schulman SP, Gerstenblith G, Weiss RG: Altered creatine kinase adenosine triphosphate kinetics in failing hypertrophied human myocardium. Circulation 2006, 114:1151-1158.

24. Bers DM: Altered cardiac myocyte Ca regulation in heart failure. Physiology (Bethesda) 2006, 21:380-387.

25. Takewa Y, Chemaly ER, Takaki M, Liang LF, Jin H, Karakikes I, Morel C, Tatsumi E, Hajjar RJ: Mechanical work and energetic analysis of eccentric cardiac remodeling in a volume overload heart failure in rats. Am $J$ Physiol Heart Circ Physiol 2009, 296:H1117-H1124

26. Ding YF, Brower GL, Zhong Q, Murray D, Holland M, Janicki JS, Zhong J: Defective intracellular $\mathrm{Ca} 2+$ homeostasis contributes to myocyte dysfunction during ventricular remodelling induced by chronic volume overload in rats. Clin Exp Pharmacol Physiol 2008, 35:827-835.

27. Giordano FJ: Oxygen, oxidative stress, hypoxia, and heart failure. J Clin Invest 2005, 115:500-508.

28. Sheeran FL, Rydstrom J, Shakhparonov MI, Pestov NB, Pepe S: Diminished NADPH transhydrogenase activity and mitochondrial redox regulation in human failing myocardium. Biochim Biophys Acta 2010, 1797:1138-1148.

29. Camors E, Monceau V, Charlemagne D: Annexins and Ca2+ handling in the heart. Cardiovasc Res 2005, 65:793-802.

30. Bouter A, Gounou C, Berat R, Tan S, Gallois B, Granier T, d'Estaintot BL, Pöschl E, Brachvogel B, Brisson AR: Annexin-A5 assembled into twodimensional arrays promotes cell membrane repair. Nat Commun 2011, $2: 270$

31. Ravassa S, Gonzalez A, Lopez B, Beaumont J, Querejeta R, Larman M, Díez J: Upregulation of myocardial Annexin A5 in hypertensive heart disease: association with systolic dysfunction. Eur Heart J 2007, 28:2785-2791.

32. Denzel MS, Scimia MC, Zumstein PM, Walsh K, Ruiz-Lozano P, Ranscht B: Tcadherin is critical for adiponectin-mediated cardioprotection in mice. J Clin Invest 2010, 120:4342-4352.

33. Shibata R, Ouchi N, Murohara T: Adiponectin and cardiovascular disease. Circ J 2009, 73:608-614

34. Mehta K, Fok JY, Mangala LS: Tissue transglutaminase: from biological glue to cell survival cues. Front Biosci 2006, 11:173-185.

35. Park D, Choi SS, Ha KS: Transglutaminase 2: a multi-functional protein in multiple subcellular compartments. Amino Acids 2010, 39:619-631.

36. Song H, Kim BK, Chang W, Lim S, Song BW, Cha MJ, Jang Y, Hwang KC: Tissue transglutaminase 2 promotes apoptosis of rat neonatal cardiomyocytes under oxidative stress. J Recept Signal Transduct Res 2011, 31:66-74.

37. Zhang Z, Vezza R, Plappert T, McNamara P, Lawson JA, Austin S, Praticò D, Sutton MS, Fitzgerald GA: COX-2-dependent cardiac failure in Gh/tTG transgenic mice. Circ Res 2003, 92:1153-1161.

38. Small K, Feng JF, Lorenz J, Donnelly ET, Yu A, Yu A, Im MJ, Dorn GW, Liggett SB: Cardiac specific overexpression of transglutaminase II (G(h)) results in a unique hypertrophy phenotype independent of phospholipase C activation. J Biol Chem 1999, 274:21291-21296.

39. Ou H, Haendeler J, Aebly MR, Kelly LA, Cholewa BC, Koike G, Kwitek-Black A, Jacob HJ, Berk BC, Miano JM: Retinoic acid-induced tissue transglutaminase and apoptosis in vascular smooth muscle cells. Circ Res 2000, 87:881-887.

40. Li $X$, Wei $X L$, Meng LL, Chi MG, Yan JQ, Ma XY, Jia YS, Liang L, Yan HT, Zheng JQ: Involvement of tissue transglutaminase in endothelin 1induced hypertrophy in cultured neonatal rat cardiomyocytes. Hypertension 2009, 54:839-844.

41. Eisenhofer G, Kopin IJ, Goldstein DS: Catecholamine metabolism: a contemporary view with implications for physiology and medicine. Pharmacol Rev 2004, 56:331-349.

42. Bianchi P, Kunduzova O, Masini E, Cambon C, Bani D, Raimondi L, Seguelas MH, Nistri S, Colucci W, Leducq N, Parini A: Oxidative stress by monoamine oxidase mediates receptor-independent cardiomyocyte apoptosis by serotonin and postischemic myocardial injury. Circulation 2005, 112:3297-3305.

43. Kaludercic N, Takimoto E, Nagayama T, Feng N, Lai EW, Bedja D, Chen K, Gabrielson KL, Blakely RD, Shih JC, Pacak K, Kass DA, Di Lisa F, Paolocci NZ: Monoamine oxidase A-mediated enhanced catabolism of norepinephrine contributes to adverse remodeling and pump failure in hearts with pressure overload. Circ Res 2010, 106:193-202.

44. Kristen AV, Kreusser MM, Lehmann L, Kinscherf R, Katus HA, Haass M, Backs J: Preserved norepinephrine reuptake but reduced sympathetic 
nerve endings in hypertrophic volume-overloaded rat hearts. J Card Fail 2006, 12:577-583.

45. Eisenhofer G, Friberg P, Rundqvist B, Quyyumi AA, Lambert G, Kaye DM, Kopin IJ, Goldstein DS, Esler MD: Cardiac sympathetic nerve function in congestive heart failure. Circulation 1996, 93:1667-1676.

46. Menazza S, Blaauw B, Tiepolo T, Toniolo L, Braghetta P, Spolaore B, Reggiani C, Di Lisa F, Bonaldo P, Canton M: Oxidative stress by monoamine oxidases is causally involved in myofiber damage in muscular dystrophy. Hum Mol Genet 2010, 19:4207-4215.

47. Kaludercic N, Carpi A, Menabo R, Di Lisa F, Paolocci N: Monoamine oxidases (MAO) in the pathogenesis of heart failure and ischemia/ reperfusion injury. Biochim Biophys Acta 2011, 1813:1323-1332.

48. Riederer P, Lachenmayer L, Laux G: Clinical applications of MAO-inhibitors. Curr Med Chem 2004, 11:2033-2043.

49. Wu Z, Li Y, Li X, Ti D, Zhao Y, Si Y, Mei Q, Zhao P, Fu X, Han W: LRP16 integrates into NF-KB transcriptional complex and is required for its functional activation. PLOS One 2011, 6:e18157.

50. Gohil VM, Nilsson R, Belcher-Timme CA, Luo B, Root DE, Mootha VK: Mitochondrial and nuclear genomic responses to loss of LRPPRC expression. J Biol Chem 2010, 285:13742-13747.

51. Wang X, Yang Z, Zhang H, Ding L, Li X, Zhu C, Zheng Y, Ye Q: The estrogen receptor-interacting protein HPIP increases estrogenresponsive gene expression through activation of MAPK and AKT. Biochim Biophys Acta 2008, 1783:1220-1228.

52. Cooper GJ, Phillips AR, Choong SY, Leonard BL, Crossman DJ, Brunton DH, Saafi L, Dissanayake AM, Cowan BR, Young AA, Occleshaw CJ, Chan YK, Leahy FE, Keogh GF, Gamble GD, Allen GR, Pope AJ, Boyd PD, Poppitt SD, Borg TK, Doughty RN, Baker JR: Regeneration of the heart in diabetes by selective copper chelation. Diabetes 2004, 53:2501-2508.

53. Grant JE, Bradshaw AD, Schwacke JH, Baicu CF, Zile MR, Schey KL: Quantification of protein expression changes in the aging left ventricle of Rattus norvegicus. J Proteome Res 2009, 8:4252-4263.

doi:10.1186/1477-5956-9-69

Cite this article as: Petrak et al:: Proteomic and transcriptomic analysis of heart failure due to volume overload in a rat aorto-caval fistula model provides support for new potential therapeutic targets monoamine oxidase A and transglutaminase 2. Proteome Science 2011 9:69.

\section{Submit your next manuscript to BioMed Central and take full advantage of:}

- Convenient online submission

- Thorough peer review

- No space constraints or color figure charges

- Immediate publication on acceptance

- Inclusion in PubMed, CAS, Scopus and Google Scholar

- Research which is freely available for redistribution

Submit your manuscript at www.biomedcentral.com/submit 